BULLETIN Bulletin hispanique

HISPANIQUE Université Michel de Montaigne Bordeaux

120-2 | 2018

Varia

The Routledge Companion to Iberian Studies, edited by Javier Muñoz-Basols, Laura Lonsdale and Manuel Delgado

London and New York, Routledge, 2017

Trevor J. Dadson

OpenEdition

Journals

Edición electrónica

URL: https://journals.openedition.org/bulletinhispanique/7509

DOI: 10.4000/bulletinhispanique.7509

ISSN: $1775-3821$

Editor

Presses universitaires de Bordeaux

Edición impresa

Fecha de publicación: 10 diciembre 2018

Paginación: 716-720

ISBN: 979-10-300-0337-6

ISSN: 0007-4640

Referencia electrónica

Trevor J. Dadson, «The Routledge Companion to Iberian Studies, edited by Javier Muñoz-Basols, Laura Lonsdale and Manuel Delgado», Bulletin hispanique [En línea], 120-2 | 2018, Publicado el 10 diciembre 2018, consultado el 08 enero 2022. URL: http://journals.openedition.org/bulletinhispanique/7509 ;

DOI: https://doi.org/10.4000/bulletinhispanique.7509

Este documento fue generado automáticamente el 8 enero 2022.

Tous droits réservés 


\section{The Routledge Companion to Iberian Studies, edited by Javier Muñoz- Basols, Laura Lonsdale and Manuel Delgado}

London and New York, Routledge, 2017

Trevor J. Dadson

\section{REFERENCIA}

The Routledge Companion to Iberian Studies, edited by Javier Muñoz-Basols, Laura Lonsdale and Manuel Delgado. London and New York: Routledge, 2017. Xxv + 717 p. - ISBN

9780415722834

1 En los últimos años los «Companions» (un tipo de compendio o volumen colectivo a menudo con diferentes autores, aunque muchos tienen solo un autor) se han hecho bastante populares. Los tenemos sobre un autor (p.e. Lope de Vega), una obra (Las novelas ejemplares de Cervantes), una época (el renacimiento, el dieciocho), un género (el cine, la comedia), una cultura (la literatura catalana), y seguramente otras divisiones que se me han escapado. Son libros pensados para alumnos universitarios y el lector general no especialista -al menos esto será el objetivo de las editoriales me parece-, aunque muchos reúnen ensayos de un nivel y calidad que fácilmente pueden servir para especialistas en el tema. A este respecto, pienso en el A Companion to Cervantes's Novelas ejemplares editado por Stephen Boyd para Tamesis Books, o A Companion to "Don Quixote" de Anthony Close (también para Tamesis). Al final, todo depende de la calidad de los autores (o el autor) encargados de la obra.

2 Aunque, como he dicho, parece haber habido una explosión en la publicación de «Companions» con varias editoriales compitiendo en el mismo mercado (Tamesis, Routledge, Oxford, Cambridge), el hecho es que tienen una larga historia. Recuerdo que 
uno de los textos recomendados en el Reino Unido para alumnos universitarios de la carrera de filología española hace ya más de cuarenta años era precisamente Peter Russell, Spain: A Companion to Spanish Studies (1973). Entonces era aún posible estudiar algo llamado español (lengua y literatura). El título del libro a reseñar, The Routledge Companion to Iberian Studies, indica el largo camino que hemos recorrido en esos años. Como queda claro en la Introducción de este libro y también en algunas de las contribuciones, la confección del libro se debe a debates contemporáneos, especialmente en el mundo anglosajón (léanse universidades norteamericanas y británicas), sobre la naturaleza de lo que enseñamos (e investigamos) en nuestros departamentos universitarios. «Filología española» o «Estudios Hispánicos», como títulos, quedan cortos hoy en día para reflejar todo lo que se enseña en un típico departamento de lengua española: ¿dónde caben el portugués (enseñado en muchos departamentos de estudios hispánicos en el Reino Unido y otras partes), el catalán, el gallego, el vasco, los estudios hispanoamericanos (estos últimos pieza clave en cualquier currículum si la idea es atraer a alumnos a la disciplina)? En los últimos años la enseñanza del español en las universidades de gran parte del mundo ha conocido una expansión sin precedentes, tanto de alumnos como de áreas a cubrir. Se han incorporado al sílabo los estudios de género, los estudios culturales, el cine, y, cómo no, en reconocimiento de la diversidad cultural y lingüística de la Península Ibérica, la lengua y cultura de las demás naciones de ella. De todo esto ha nacido el proyecto llamado «Iberian Studies» [estudios ibéricos], y con él la razón de ser de este Companion.

Dividido en cinco partes cronológicas -medieval, siglos de oro, siglos dieciocho y diecinueve, siglo veinte, siglo veintiuno- y cada una de ellas en dos secciones -1) historia, política y estudios culturales; 2) literatura y cultura visual- con cinco contribuciones por sección, el libro consiste en 50 ensayos de reconocidos especialistas (la mayor parte) mezclados con aportaciones de profesores más jóvenes y menos conocidos. Mantener un nivel académico alto con tantas contribuciones es ya de por sí difícil, pero este libro lo consigue, y con creces. Cuando empecé a leer el Routledge Companion to Iberian Studies, no esperaba, si he decir la verdad, gran cosa, ya que me parecía casi imposible que un libro tan largo con tantos contribuyentes procedentes de países y sistemas universitarios tan distintos consiguiera y luego mantuviera mi interés por la calidad de sus ensayos, pero me equivoqué y la lectura de este libro ha sido más que gratificante. He aprendido algo de casi todas las contribuciones, algo nuevo y, en muchos casos, algo de valor para mis propios estudios e intereses. El libro no pretende cubrir todo, algo imposible incluso con 50 capítulos, pero lo que ofrece es en muchos casos novedoso, inesperado y sugerente. A pesar de seguir una cronología tradicional y una división también tradicional entre historia y literatura, el contenido de los distintos capítulos no es siempre lo que uno esperaría, y el lector va a encontrar autores, textos, películas no siempre tradicionales ni muy conocidos. Esto está muy bien y ayuda a dar una idea amplia y profunda de lo que pueden ser «Iberian Studies».

Obviamente, el libro tiene sus problemas: ¿cómo se puede abarcar todo lo que puede significar el término «Iberian Studies» en un libro, por muchas contribuciones que tenga? Y, tal vez de mayor importancia, ¿cómo se consigue incluir en cada ensayo (o la mayor parte de ellos) referencias sólidas, válidas y beneficiosas para las demás culturas de la Península Ibérica fuera de la castellana, es decir, la portuguesa, gallega, vasca y catalana? El peligro aquí es que el libro acabe siendo poco más que un tipo de guía de estudios comparados de la Península. En algunos de los ensayos se nota esta tensión: la tensión entre tratar un tema académicamente válido mientras que se tiene que incluir 
obras (sean novelas o películas, por ejemplo) de autores de otra parte de la Península que poco o nada tienen en común con el tema principal. En estos casos las referencias pueden parecer como una ocurrencia tardía y superficial, como si el autor o la autora se estuviera diciendo: «ahora me toca mencionar a tal autor o tal obra». Naturalmente, algunos ensayos consiguen superar este desafío mejor que otros, y los resultados son interesantes y reveladores. El ver el mismo problema o el mismo tema desde distintas perspectivas lingüísticas y culturales (pero siempre dentro de la Península Ibérica) crea un valor añadido y significa que el libro ha merecido la pena.

Otro problema en potencia para algunos lectores será sin duda la inclusión de algunas áreas y la falta de otras. Para dar algunos ejemplos: disfruté mucho de las dos primeras contribuciones a la primera parte «Medieval Iberia» sobre las tradiciones festivas en Castilla y Aragón (cap. 1) y el peregrinaje a Santiago (cap. 2), pero noté la falta de un capítulo que diera alguna idea, por incompleta que fuera, del desarrollo histórico de la península entre los siglos ocho y quince (que es el período que abarca la primera parte del libro). Para un alumno que tiene poca idea de este período de la historia (es decir, la gran mayoría), los cinco capítulos que supuestamente lo tratan aquí lo van a dejar confuso y con grandes lagunas en sus conocimientos. En la sección de literatura y arte visuales, el que no haya nada sobre la épica, seguramente un género que podía haber sido tratado a nivel ibérico, o sobre los cronistas (que podía haber dado lugar a una buena confrontación histórico-literaria entre Fernão Lopes, de Portugal, y Pedro López de Ayala, de Castilla), es algo difícil de entender. Más difícil aún resulta la exclusión de la poesía cortesana escrita en gallego (por castellanos) o la conjunción de la literatura y las artes visuales en, por ejemplo, las Cantigas de Santa María (escritas también en gallego-portugués). Por otro lado, se agradece mucho la inclusión de un capítulo sobre la poesía medieval hebrea y musulmana escrita en romance.

6 El siguiente período (siglos XVI y XVII) sale mejor parado en cuanto al tratamiento histórico y político (con, por ejemplo, un capítulo muy sugerente sobre los imperios portugués y español, y otro con una lectura muy fina de los seis cuadros encargados por Felipe III para celebrar la expulsión de los moriscos), pero peor en cuanto a la parte literaria y visual. Cubrir lo que era, tal vez, el mayor período de esplendor artístico de la península en solo cinco capítulos siempre iba a ser un reto, pero que no haya nada sobre la poesía, cuando es el género que más que ningún otro juntó a los grandes autores de Portugal y Castilla (Garcilaso, Sá de Miranda, Camões, Góngora, Lope, Quevedo), especialmente cuando algunos escribían en ambas lenguas, crea un vacío inexplicable. Lo mismo pasa con las artes visuales. Incluir un capítulo sobre los mitos de Ícaro y Faetón y cómo fueron representados en la literatura emblemática y los techos pintados de la Casa de Pilatos y la Casa de Arguijo de Sevilla es un lujo poco explicable cuando no hay nada sobre los grandes pintores de la época. En esto la siguiente sección (siglos XVIII y XIX) sale mejor tratada con un capítulo titulado «Painting in the Spanish Enlightenment: artists at court and in the academy».

7 Algo que se podía haber explorado, y que habría dado un toque especial al libro, habría sido la literatura castellano-aragonesa aljamiada. La exploración de una literatura islámica escrita en castellano mediante caracteres arábigos, pero con una fuerte dosis de influencias cristianas (se han encontrado huellas de, por ejemplo, La Celestina en alguna obra), cumple a la perfección la idea de unos estudios ibéricos abiertos a todas las corrientes y tradiciones de una península multicultural y plurilingüe. 
Cuando nos acercamos a períodos más contemporáneos, los problemas de este tipo aumentan, al faltarnos el beneficio del tiempo y la perspectiva histórica. A modo de ejemplo, el capítulo 43 sobre la democracia, los indignados y la tradición republicana ya parece algo anacrónico, sobrepasado por eventos posteriores. Los indignados del 15M han desaparecido del mapa (al igual que sus correligionarios del movimiento «Occupy» de otras partes del mundo) y aunque algunos se han convertido en partidos políticos como «Podemos», estos también corren el riesgo de desaparecer pronto, si nos atenemos a las últimas encuestas de opinión e intención de voto. Cualquier análisis de la situación en Cataluña (hecha antes de 2017, año de publicación del libro) corre mayores riesgos de anacronismo histórico. Lo mismo pasa con las contribuciones sobre literatura. Aunque me parecieron muy meritorios los capítulos sobre las novelas gráficas y la ficción reciente, tanto en castellano como en gallego, vasco y catalán, la elección de autores y títulos resultó muy azarosa y, en algunos casos, discutible. Y, de nuevo, ni un capítulo sobre la poesía. En cuanto a la sección sobre literatura y cultura visual del siglo XX, me sorprendió que hubiera dos contribuciones sobre el cine (de un total de cinco) y algo sobre la novela español de posguerra, pero nada en absoluto sobre la novela neorrealista portuguesa (uno de los grandes logros de la ficción portuguesa del XX, con autores de la talla de Carlos de Oliveira, Fernando Namora, Agustina BessaLuís, Alves Redol, Augusto Abelaira, y otros muchos), que fácilmente se podía haber comparado con la novela realista española de la misma época. A fin de cuentas, eran dos tradiciones literarias intentando luchar con (y sacar sentido de) la realidad de sus respectivas dictaduras.

Repito: son críticas (y no son determinantes) que solo la lectura de este fascinante libro ha originado, porque mientras que algunas contribuciones metían a autores y temas de distintas partes de la Península de manera algo forzada y poco convincente, existían otras posibilidades (como he sugerido arriba) de poder demostrar la enorme riqueza, parecidos y diferencias entre las lenguas y culturas de Iberia. Las contribuciones que consiguieron esto eran la mayoría, y para esto el lector ha de agradecer a los editores del volumen. Sin duda alguna, habrá contribuido al debate tan acalorado ahora mismo sobre el cómo designar lo que enseñamos e investigamos y cómo titular los departamentos donde llevamos a cabo nuestra actividad docente -si es que todavía tenemos departamentos independientes con cierto control sobre el currículum, otra especie en vías de extinción, por lo que veo-.

Para terminar con una anécdota: el departamento donde acabé mi carrera profesional (en la Queen Mary University of London) ha pasado por todas las fases de este debate (que por tanto no es nada nuevo). En su principio se llamaba Departamento de Español; luego pasó a llamarse Departamento de Estudios Hispánicos; el siguiente paso era Departamento de Estudios Ibéricos e Hispanoamericanos [«Iberian and Latin American Studies»], que es cuando yo me uní a él. (Curiosamente, habíamos cumplido con los objetivos del libro bajo reseña.) Finalmente, decidieron cambiar el nombre otra vez, a Departamento de Estudios del español, portugués, catalán e Hispanoamérica, que bien poco ha durado, ya que ahora el departamento como tal ha desaparecido para acabar en un Departamento de Lenguas Modernas, donde la especificidad de cada una se ha perdido totalmente. Tal vez en todo este peregrinaje lingüístico haya una lección valiosa: las designaciones al final valen bien poco. Cómo llamamos lo que enseñamos es mucho menos importante que defender esta docencia contra los bárbaros que nos rodean, y cada vez con más saña. Ahora bien, si alguien duda de la vitalidad de nuestra 
disciplina, llámese lo que se quiera, que lea este libro de tapa a tapa, porque allí va a encontrar más de una razón para enorgullecerse de ella.

\section{AUTORES}

TREVOR J. DADSON

Queen Mary University of London 